Maestría en Historia y Memoria

\title{
Besse, Juan y Escolar, Cora (Ed.). (2019). Políticas y lugares de la memoria. Figuras epistémicas, escrituras, inscripciones sobre el terrorismo de Estado en Argentina. Buenos Aires: Miño y Dávila Editores, $310 \mathrm{pp}$.
}

\section{Agustina Cinto}

Centro de Investigaciones Sociales-Instituto de Desarrollo Económico y Social /

CONICET. Universidad Nacional de Rosario, Argentina

cintoagustina@gmail.com

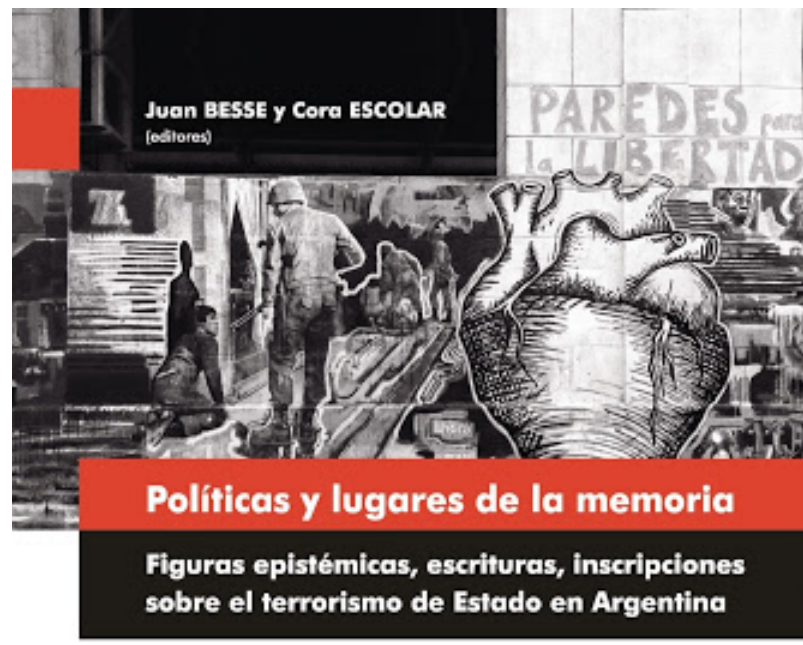

Meriel Ajenvo | Juan Basse | Jimena Beland y Cestila | Core Escoler | Silvina Fabri Gabriel Margiotto | María Eugenia Mendizabal | Luciano Messina | Cocila Palories

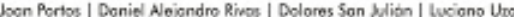

En el año 2002 se inició en Argentina un proceso por el cual gran parte de los espacios físicos que funcionaron como centros clandestinos de detención (CCD) durante la última dictadura fueron constituyéndose en sitios de memoria. En el particular entramado que, en estos lugares, componen las prácticas militantes, los saberes expertos, los dispositivos testimoniales y las estrategias institucionales de gestión, nacen los análisis que integran Politicas y lugares de la memoria. Figuras epistémicas, escrituras, 
inscripciones sobre el terrorismo de Estado en Argentina. Las investigaciones que dan vida a este libro se inscriben en el trabajo producido por el Equipo Lugares y Políticas de la Memoria, con sede en el Instituto de Geografía Romualdo Ardissone, Facultad de Filosofía y Letras de la Universidad de Buenos Aires, en el cruce de la Antropología, la Sociología, la Geografía y las Ciencias de la Comunicación.

La mayoría de estas investigaciones habían sido publicadas previamente en revistas académicas. Sin embargo, su reunión en este libro vuelve palpable el trabajo colectivo gestado en el marco del Equipo, exhibiendo líneas de continuidad teóricas, metodológicas y epistemológicas que los hilvanan entre sí: la impronta antropológica del abordaje local de casos; la perspectiva foucaultiana acerca del poder, los discursos y dispositivos; el análisis institucional; las conceptualizaciones sobre memorias de la política y políticas de la memoria de Rabotnikof; y los aportes del psicoanálisis, por mencionar las más destacadas. Los dieciocho capítulos que integran Políticas y lugares de la memoria se encuentran organizados en cuatro partes, que se configuran como ejes de trabajo: I. Políticas y lugares de la memoria: derivas epistémicas, puntuaciones teóricas; II. Lugares de la memoria: itinerarios, perspectivas; III. Estrategias de gestión y dispositivos memoriales; y IV. Testimonio, memoria y escritura.

La presentación del libro está en manos de Juan Besse y Cora Escolar, sus editores y directores del Equipo, quienes establecen algunas coordenadas para recorrerlo. Las políticas y los lugares de la memoria, que se construyen en los anudamientos entre prácticas, saberes, testimonios y gestión, son lugares de partida, pero también de llegada, productos del trabajo colectivo. Atraviesan este proceso una serie de figuras epistémicas sobre el terrorismo de Estado que no pueden ser pensadas universalmente: desaparecidos, ex CCD, grupos de tareas; y que nacen de la tensión entre escrituras e inscripciones: "materialidades significantes y físicas que coexisten en la singularidad de cada sitio de memoria y de los modos en que esos sitios trabajan en la reparación simbólica y, en ocasiones, judicial, del daño cometido" (Besse y Escolar, 2019, p. 13). Lejos de fragmentar la línea central del libro, la cantidad de capítulos condice con lo destacado en esta presentación: que la relación de estas figuras epistémicas con las políticas y los lugares de la memoria requiere ser pensada cada vez, en la particularidad de cada caso.

Besse abre la primera parte con el capítulo titulado "Conjeturas acerca de las condiciones históricas de posibilidad de las políticas de la memoria sobre el terrorismo de Estado: la singularidad argentina”, mediante el análisis de aquellas desarrolladas desde el año 2003. El autor destaca la relevancia del vínculo que sostienen las memorias de la política y las políticas de la memoria. Presenta una serie de acepciones del término políticas de la memoria que, aunque actúan en diferentes dimensiones, se articulan entre sí, considerando sus condiciones históricas, políticas y culturales de posibilidad en clave nacional. En el capítulo dos, "La cuestión del tiempo: los observatorios de derechos humanos como políticas públicas de la memoria”, Escolar propone abordar el modo en que los grupos sociales e instituciones experimentan la dimensión temporal, en el marco de la construcción de observatorios de derechos humanos en diferentes provincias argentinas entre 2005 y 2007 por parte del Estado nacional. La autora delimita las categorías de tiempo político y de tiempo social y desarrolla su articulación para analizar estos dispositivos institucionales y las relaciones conflictivas entre Estado y sociedad civil. "Sitios y lugares de la memoria: dimensiones, experiencias y controversias" es el título del tercer capítulo, donde Luciana Messina ofrece un conjunto de precisiones teórico-conceptuales en torno a la espacialización de memorias ligadas a procesos políticos represivos y de violencia estatal. Propone posibles entradas para el análisis de los espacios de memoria: sus procesos políticos de construcción, las prácticas sociales de utilización de los mismos, las estrategias de representación y transmisión que se construyen en ellos, y las producciones culturales que los abordan. Escolar y Cecilia Palacios escriben el cuarto capítulo: "Memoria y vida. Apostillas epistemológicas sobre la gestión de la memoria”. Desde la perspectiva foucaultiana acerca de la eficacia de los discursos, piensan el discurso político presente en estos procesos de gestión. Las autoras destacan las selecciones, reinterpretaciones, los dilemas éticos y políticos que atraviesan a la memoria como discurso, señalando que su capacidad de transmisión es lo que la torna social y, en clave de futuro, permite su articulación con "una ética de la vida". En el quinto capítulo, "Hacia un estado de la cuestión sobre la 
relación entre memoria y política”, Dolores San Julián brinda un recorrido por diferentes referentes teóricos para abordar la distinción entre lo político y la política, relacionando estos términos, respectivamente, con lo instituido y lo instituyente. Acerca del vínculo entre memoria y política, precisa que lo/la político/a resulta objeto de la memoria, mientras que ésta es práctica política y, a la vez, objeto de prácticas políticas.

La parte dos comienza con el capítulo seis, "Pensar la institucionalización en el territorio desde el caso Predio Quinta Seré”. Aquí Escolar y Silvina Fabri se preguntan por las relaciones que la territorialidad \#articulada con la hechura institucional\#, establece con el área que delimita, las prácticas sociales y memoriales y las relaciones de poder, para comprender de qué modo la memoria es gestionada y administrada en torno a La Casa de la Memoria y la Vida. En "Fronteras difusas entre gestión y militancia: actores, debates y tramas memoriales en la institucionalización del ex CCD “'Olimpo' como espacio de memoria”, capítulo siete, Messina analiza algunas tensiones y disputas de sentido en la cogestión de políticas de la memoria en el lugar entre 2004 y 2007. Para ordenar los debates de aquellos años establece tres momentos: de resistencia, de construcción y de afirmación; a través de los cuales los actores involucrados desplegaron diferentes posiciones respecto al Estado, produciendo, a su vez, lo estatal en ese movimiento. En el octavo capítulo, "Producción del espacio urbano y prácticas institucionales. El caso del Espacio para la memoria y para la promoción y defensa de los derechos humanos (Ex ESMA)", Escolar y Palacios parten de Guattari y Foucault para proponer un análisis micropolítico-institucional-territorial del sitio, donde el testimonio de sobrevivientes se presenta como elemento central en las visitas guiadas, espacializando la subjetividad y la memoria. Escolar y Fabri, en el capítulo nueve: "La reconstrucción del pasado en el presente. El caso del Espacio Mansión Seré", trabajan sobre la espacialización del recuerdo y el modo de conceptualizar este caso como lugar de memoria. En la articulación de desarrollos teóricos provenientes del giro cultural en Geografía y otros acerca de lugares de memoria, éstos son concebidos como espacios vividos, donde los sujetos negocian con otros el uso y apropiación física del lugar, abriendo la posibilidad a la apropiación simbólica. "La potencia de lo dicho. El nombre 'Automotores Orletti”" es el capítulo diez, en el que Mariel Alonso, Jimena Boland y Castilla, Joan Portos y Daniel Alejandro Rivas estudian los modos en que se asoció esta denominación al CCD, revisando las articulaciones entre las políticas de la memoria, los sentidos barriales y el discurso jurídico, para reconstruir la influencia de una política de la memoria en los recuerdos de los vecinos del barrio respecto al nombre del lugar.

Inicia la tercera parte el capítulo once: "Diálogos entre la investigación académica y la gestión en la reconstrucción de una política de la memoria”, donde Messina y María Eugenia Mendizábal recorren el desarrollo de la política de la memoria en el ex CCD Olimpo, desde sus experiencias académicas y de gestión entre 2005 y 2010. Reconocen la existencia de una matriz en dicha política, sostenida en las prácticas que configuran al sitio como dispositivo político. En "Tensiones etnográficas y lógicas de la gestión: experiencias en el campo de las políticas públicas de la memoria en tres sitios”, capítulo doce, Alonso, Portos y San Julián reflexionan sobre sus participaciones, durante la primera década de los años 2000, en los ex CCD Mansión Seré, Automotores Orletti y Olimpo, poniendo la mirada en la tensión entre las prácticas de gestión y académicas, particularmente, desde la Antropología. En el capítulo trece, "El arte conmemorativo en la lugarización de la memoria. Construcción simbólica y narrativa en el Predio Quinta Seré”, Fabri examina la instalación artística "Las huellas del fuego", inaugurada en el sitio en 2006, para pensar los efectos del vínculo entre arte, estética, memoria y política en el proceso de lugarización de la memoria. Concebida a modo de conmemoración, la obra adquiere nuevos significados y es iluminada desde el presente cada vez, como parte de la trama memorial y narrativa del lugar. Portos escribe el capítulo catorce, "Usos y controversias acerca de lo sagrado en ex centros clandestinos de detención: entre los casos ejemplares y los ejemplos sobre los casos", en el que se pregunta por los usos posibles en estos espacios, en relación a lo sagrado como categoría nativa y conceptual. Posicionado como investigador y trabajador estatal en varios sitios de memoria, analiza algunas particularidades de esta cuestión en los ex CCD ESMA y, con mayor detenimiento, en el ESIM (Mar del Plata). En el capítulo quince, "Estrategias de representación y transmisión del pasado reciente en el Espacio 
Mansión Seré (2013-2016)", Gabriel Margiotta aborda los soportes materiales y estrategias de transmisión del pasado reciente en dicho sitio, centrado en la narrativa construida por el equipo de investigación y conservación arqueo-antropológico, y el lugar que tiene en ella la imaginación.

La cuarta y última parte del libro comienza con el capítulo dieciséis: "Testimonios coalescentes: emergencias de la razón militante sobre la fuga del centro clandestino de detención Atila/Mansión Seré”. Besse y Messina indagan en la confluencia de testimonios acerca de este caso excepcional y emblemático, para analizar la violencia del terrorismo de Estado y cómo fue pensada mediante estos testimonios, considerando las temporalidades que los tornan posibles y su relación con una razón militante. En el capítulo diecisiete, “Testimonio y escritura: ejercicios escriturales, transmisión de la memoria”, Luciano Uzal propone pensar las vinculaciones entre literatura, testimonio y memoria. El autor se pregunta por la posibilidad de testimoniar ante los vacíos significantes que generan las vivencias traumáticas. En estos casos, la palabra, como modo de relacionarse con otro, puede trascender lo somático, "salvar el sentido", y desde allí, producir memoria frente al horror. El capítulo dieciocho, "Diferentes registros en los testimonios de sobrevivientes del terrorismo de Estado”, cierra esta edición. Alonso y Portos analizan cómo las particularidades del proceso judicial incidieron en las formas del testimonio acerca de la experiencia en los CCD a través del tiempo, considerando el lugar que las memorias de la política y su articulación con las políticas de la memoria han tenido en ello.

Políticas y lugares de la memoria da cuenta de las complejas y múltiples interrelaciones, que tramando lo universal, lo particular y lo singular, pueden establecerse entre memorias, políticas y lugares respecto al terrorismo de Estado. Las investigaciones que integran este libro, aunque situadas mayormente en Capital Federal y Gran Buenos Aires, son una referencia ineludible para continuar reflexionando sobre las particularidades que adquiere cada sitio de memoria en nuestro país y habilitar comparaciones con casos en otras partes del mundo. 